\title{
A new approach in ureteral access sheath locating in retrograde intrarenal surgery (RIRS) by endovisional technique
}

\author{
Mehmet Giray Sönmez, Cengiz Kara \\ Department of Urology, Medical Park Ankara Hospital, Ankara, Turkey.
}

\begin{abstract}
Summary Objective: To compare the results of patients who underwent retrograde intrarenal surgery (RIRS) using endovisional technique for ureteral sheat locating with control group in which endovisional technique was not applied. Material and Methods: Of the 41 patients who underwent RIRS treatment for kidney stone, between March 2014August 2015, 19 patients treated with endovisional technique formed the study group and remaining 22 patients formed the control group. Patients were evaluated for age and gender, baseline and post procedural creatinine level, duration of operation, fluoroscopy and hospitalization time, size and localization of the stone, presence of multiple stones, previous shock wave lithotripsy (SWL) procedure, double J catheter requirement, complication rate, residual stone rate and absence of stone ratio.

Results: There was no statistically significant difference between age, gender, location of the stone, previous SWL procedure, presence of multiple stones, baseline and postprocedural creatinine level, absence of stone ratio, double J catheter requirement and hospitalization duration between the groups. The duration of operation and fluoroscopy of the patients were significantly shorter than the control group ( $p=0.036$ and $p<0.001$, respectively). The complication rates of the endovisional technique group was significantly lower than that of the control group ( $p=0.032)$. Conclusion: Endovisional technique is considered to be an appropriate and useful technique in order to locate the sheath safely in patients who has difficulty in ureteral access sheath locating and to decrease the duration of operation and fluoroscopy.
\end{abstract}

KEY WORDS: Kidney stone; Laser lithotripsy; Retrograde Intrarenal Surgery (RIRS); Flexible ureterorenoscopy; Endovisional technique.

Submitted 2 December; Accepted 15 December

\section{INTRODUCTION}

As the result of developments in urinary stone disease treatment, kidney stones which could only be treated by open surgery before can be treated with minimal invasive methods such as percutaneous nephrolithototomy (PNL), retrograde intrarenal surgery (RIRS), shock wave lithotripsy (SWL) and laparoscopic stone surgery.
A new era started after the use for the first time of rigid ureterorenoscopy and ultrasonic lithotripter for kidney pelvic stone by Huffman et al. in 1983 and usage of this surgery increased progressively (1). After development of new generation flexible ureterorenoscopes (f-URS) and active and safe lithotripters, retrograde intrarenal surgery became an important alternative to surgical stone treatment. The aim of kidney stone treatment is to provide the least morbidity and achieve no stone state. For this reason, according to European Association of Urology guidelines, RIRS and SWL were suggested as the first choice in the treatment of kidney stones smaller than 2 $\mathrm{cm}$. RIRS is used as the primary treatment in kidney stones in which SWL treatment was unsuccessful and in patients who have stones under $2 \mathrm{~cm}$ or muscle-skeletal deformities or bleeding diathesis or who are obese $(2,3)$. Routine use of ureteral access sheath during RIRS is still under discussion.

Advantages of using ureteral access sheath are making ureteroscope access easier, decreasing kidney inner pressure and increasing the excretion of stone fragments and the visual quality during operation $(4,5)$.

There are studies with different views which state that ureteral access sheath increases the stone free rate and conversely that use of access sheath doesn't affect stone clearance $(6,7)$.

The disadvantage of using ureteral access sheath is potential ureteral injury related to the dimensions (8). Yet the routine usage is recommended in literature as it decreases operation time and costs and is associated with very low morbidity when used during RIRS.

In our clinic, RIRS operations are made by using ureteral access sheath.

Sometimes even in young patients, the sheath cannot pass the prostate and the bladder neck causing prostatic urethra and bladder neck injuries and serious urethrorrhagia. Again during the operation, long term erections which may take place in male patients make the operation more difficult.

These experiences made us to search for a different technique for placement ureteral access sheath. Our aim in this article was to describe the surgical technique we used (Endovisional technique) and our findings in patients we applied this technique. 


\section{MATERIAL AND METHODS}

Of the 41 patients who underwent RIRS treatment for kidney stone, between March 2014-August 2015, 19 patients were treated with the endovisional technique forming the study group and the remaining 22 patients formed the control group. Patients were evaluated for age and gender, baseline and post procedural creatinine level, duration of operation, fluoroscopy and hospitalization, size and localization of the stone, presence of multiple stones, previous SWL procedure, double J catheter requirement, complication rate, residual stone rate and stone free rate. Semirigid ureterorenoscopy was always performed before RIRS in order to evaluate possible ureter pathologies in all patients. Ureteral access sheath was placed in the control group under fluoroscopic control whereas ureteral access sheath was placed in yhe other patients with the Endovisional Technique. Lithotripsy with Holmium laser was used to fragment the stones. Patient evaluation in the postoperative first month was made with ultrasonography (USG) and direct urinary system X-graphy (DUSG). Absence of residual stone fragments over $4 \mathrm{~mm}$ was considered as a success. Our complications were classified in accordance with the modified Clavien system.

Age, creatinine level before and after the operation, size of the stone, duration of operation, fluoroscopy and hospitalization were statistically compared between groups with Mann-Whitney $\mathrm{U}$ and gender, stone localization, presence of multiple stones, previous SWL procedure, residual stone occurence rate, complication rate, double $\mathrm{J}$ catheter requirement and stone free rate with Pearson chi-square. A $\mathrm{p}<0.05$ value was accepted as statistically significant. Statistical evaluation of data was made using SPSS 15 for Windows.

\section{Surgical technique}

General anesthesia was preferred in all patients, because the patient can feel pain and variable breathing movements cannot be prevented under regional anesthesia and undesired traumas may develop if the patient is less relaxed The operation was made in dorsal lithotomy position as standard. Ureter was dilated up to the proximal tract by entering with $8 \mathrm{~F}$ semi-rigid ureterorenoscope before RIRS. After that, an hydrophilic guide wire was placed with the help of semi-rigid ureteroscope under fluoroscopy. As ureteral access sheath, a 10/12 F $45 \mathrm{~cm}$ sheath was generally preferred. The end of the sheath was cut about $3 \mathrm{~cm}$ with straight borders without any burrs and ridges using a scalpel in consideration of the length of the ureteroscope $(43 \mathrm{~cm})$ so that it would be $1 \mathrm{~cm}$ outside the sheath. After that, the sheath was positioned on the $8 \mathrm{~F}$ semi-rigid scope and located by endoscopic guidance (Figure 1).

Fluoroscopic imaging was used to evaluate the ureter from outside during its placement (Figure 2). After that a $7.5 \mathrm{~F}$ flexible ureterorenoscope was passed inside the sheath (Karl Storz flex X2, Germany) and the kidney was reached. The stones were broken by Holmium laser lithotripter and big fragments were extracted with a nitinol basket. A month later, patients were evaluated for stones by DUSG and USG. Fragments under $4 \mathrm{~mm}$ were considered unimportant.
Figure 1.

Image of THE ureteral access sheath placed on the ureteroscope.

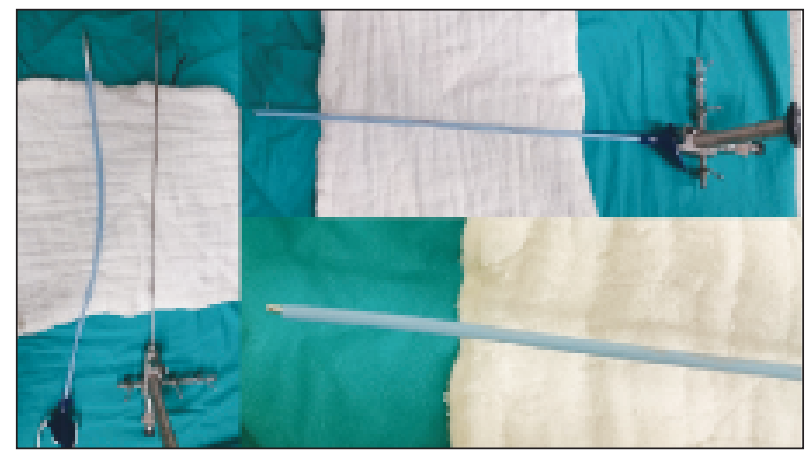

Figure 2.

Placement of the ureteral access sheath by endovisional technique.

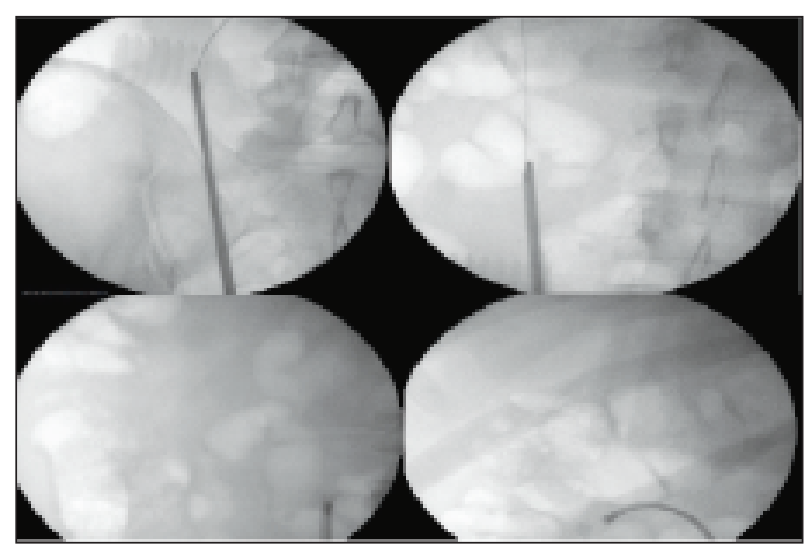

\section{RESULTS}

There was no statistically significant difference between age, gender, location of the stone, previous SWL procedure, presence of multiple stones, baseline and postprocedural creatinine level, absence of stone ratio, double J catheter requirement and hospitalization duration between the groups.

Duration of operation was $82.6 \pm 9.8$ (49.2-125.6) minute ( $\mathrm{min}$ ) in the endovisional technique group and $106.8 \pm 11.4$ ( 57.8-162.4) min. in the control group. Duration of fluoroscopy was $20.1 \pm 6.7$ (8.7-32.4) second (sec) in the endovisional technique group and 42.3 $\pm 9.2(16.7-65.6) \mathrm{sec}$. in the control group.

Duration of operation and fluoroscopy was significantly shorter in the endovisional group compared to the control group. ( $p=0.036, p<0.001$, respectively).

Major complication did not develop in any of the patients. Clavien grade 1-2 complications developed in 5 patients in endovisional technique group $(26.3 \%)$ and in 9 patients in the control group (40.9\%). Complication rate demonstrated was significantly reduced in the study group compared to the control group $(p=0.032)$. A double-J catheter was located in order to prevent mucosal edema and make easier the passage of small stone fragments $(31.5 \%$ in the study group and $31.8 \%$ in the control group). No difference 
Table 1.

Surgery related and postoperative findings $n=41(19 / 22)$.

\begin{tabular}{|c|c|c|c|}
\hline & Endovisional technique group $n=19$ & Control group $n=22$ & $p$ value \\
\hline Age & $46.2 \pm 8,1(22-71)$ & $43,4 \pm 8,7(20-67)$ & $p=0,386$ \\
\hline Sex & $8 \mathrm{~W} / 11 \mathrm{M}(42,1 / \% 57,8 \%)$ & 10W/12M (45,4/\%54,5\%) & $p=0,318 / p=0,421$ \\
\hline Stone size $(\mathrm{mm})$ & $10,3 \pm 1,7(7,2-15,4)$ & $10,8 \pm 1,9(6,9-14,7)$ & $p=0,173$ \\
\hline$\overline{\text { Right-left }}$ & $11 / 8(57,8-42,1 \%)$ & $11 / 11(50 / 50 \%)$ & $p=0,09 / p=0,07$ \\
\hline Lower Calyx & $11(57,8 \%)$ & $13(59,1 \%)$ & $p=0,218$ \\
\hline Renal pelvis & $5(26,3 \%)$ & $6(27,2 \%)$ & $p=0,329$ \\
\hline Medium calyx & $3(15,7 \%)$ & $3(13,6 \%)$ & $p=0,167$ \\
\hline Multiple stones & $5(26,3 \%)$ & $4(18,1)$ & $p=0,146$ \\
\hline Previous SWL procedure & $7(36,8 \%)$ & $8(36,3 \%)$ & $p=0,514$ \\
\hline Preoperative average creatinine $(\mathrm{mg} / \mathrm{dl})$ & $0,63 \pm 0,07$ & $0,81 \pm 0,06$ & $p=0,09$ \\
\hline Postoperative average creatinine (mg/dl) & $0,86 \pm 0,08$ & $0,94 \pm 0,07$ & $p=0,131$ \\
\hline Duration of operation (min) & $82,6 \pm 9,8(49,2-125,6)$ & $106,8 \pm 11,4(57,8-162,4)$ & $p=0,036$ \\
\hline Duration of fluoroscopy (sec) & $20,1 \pm 6,7(8,7-32,4)$ & $42,3 \pm 9,2(16,7-65,6)$ & $p<0,001$ \\
\hline Grade 1, 2 complication according to modified Clavien system & $5(26,3 \%)$ & $9(40,9 \%)$ & $p=0,032$ \\
\hline Grade 3, 4, 5 complication according to modified Clavien system & 0 & 0 & \\
\hline Duration of hospitalization (hours) & $21,4(13,3-49,2)$ & $25,2(16,8-52,4)$ & $p=0,413$ \\
\hline Double J catheter requirement & $6(31,5 \%)$ & $7(31,8 \%)$ & $p=0,591$ \\
\hline Stone free rate & $16(84,2 \%)$ & $18(81,8 \%)$ & $p=0,392$ \\
\hline
\end{tabular}

was observed between the groups in the need for double-J catheter $(p=0,591)$. A significant postoperative creatinine increase was not observed in each of the two groups. All patients were evaluated with ultrasonography and direct urinary system graphy (DUSG) in the 1st month control. Stones of $4 \mathrm{~mm}$ or smaller were considered as clinically insignificant. Stone free rate was assessed in $84.2 \%$ in the study group and $81.8 \%$ in the control group. $(p=0.392)$. Data of procedures and patients are summarized in Table 1.

\section{Discussion}

Routine use of ureteral access sheath during f-URS is still under discussion. Use of the ureteral access sheath has many advantages such as making ureteroscope access easier, decreasing kidney inner pressure and increasing the excretion of stone fragments and the visual quality during the operation $(4,5)$. Ureteral access sheath atraumatically dilates the distal ureter and make recurrent ureter entrances and exits easier (9). Takayasu and Aso used Teflon tube along the ureter in 1974 for the first time (10). Newman et al. introduced the first ureteral access sheath providing the initial basis of ureteral access sheaths used today through progressive refinements $(11,12)$. On the other hand it was claimed that ureteral access sheath use prevented the breaking and damaging of ureteroscope and prolonged its life $(9,13)$.

The disadvantage of using ureteral access sheath is potential ureteral injury related to the dimensions. Traxer et al. stated in their prospective study that ureteral access sheaths may cause injuries of the ureteral wall (8). If ureteral access sheath placement is not made under direct vision, presence of pathologies such as a stone or a tumor in distal and mid ureter may be overlooked. It is reported that ureteral access sheath usage may cause preoperative and postoperative complications such as ureter perforation, mucosal damage, urine extravasation and ureteral narrowing (14-16). Ureteral integrity damages occurred during the placement of ureteral access sheath consist of $50 \%$ of iatrogenic injuries (8).

Using of ureteral sheath in our clinic, we observed that the sheath sometimes couldn't pass the prostatic urethra and the bladder neck even in young patients and that it could cause injuries in prostatic ureter and bladder neck. In some patients we observed that even under general anesthesia, long term penile erections took place due to the irritation and trauma. This condition makes placement of the sheath over the guide much difficult. For this reason we searched for a different technique for safe placement of the ureteral access sheath.

Ureteral access sheath is located in ureter over the guide as a routine (17). Too much force could be applied in this technique and this may cause damage and the formation of fake paths in the ureter and even ureter perforation. The complication rates of the endovisional technique group was significantly lower than that of the control group ( $\mathrm{p}=0,032)$.

When the ureteral access sheath is located under direct view, pathologies present inside the ureter can be evaluated and passed easily and the sheath can be advanced in narrow passages at level of the prostatic urethra and ureteral orifices. Furthermore the pressure applied to the ureter can be adjusted. Consequently the operation and fluoroscopy time are shortened and the ureteral access sheath is located more safely and quickly. Average operation time was measured as 82.6 minutes in endovisional technique group and fluoroscopy time as $20.1 \mathrm{sec}$. The 
duration of fluoroscopy and operation were significantly shorter compared to the control group $(\mathrm{p}<0.001, \mathrm{p}=$ 0.036 respectively). In two different recent studies about the use of ureteral access sheath, the fluoroscopy time was measured as 39 and $52.72 \mathrm{sec}(18,19)$. This figures demonstrates that the Endovisional technique significantly shortens fluoroscopy time.

Stone free rate in all studies published recently range $79 \%-100 \%(6,20-22)$. This rate is similar to that observed in our study too (84.2\%), although no significant difference was observed in comparison to the control group $(\mathrm{p}=0.392)$.

Wu et al. suggested that at the end of the operation, a double-J catheter should be put in all patients after ureteral access sheath application (23). In absence of trauma and when no residual stone was present, it was reported that stent was not needed and that no complication was observed $(24,25)$.

Rapoport et al. suggested stent application in their study of 161 patients (26). Ozyuval et al. stated that the stent application increased the operation time and morbidity (18). In order to make the reduce mucosal edema and facilitate small stone fragment passage, we located a double-J catheter in six patients (31.5\%) who had endovisional technique operation and in 7 patients in the control group (31.8\%). When compared with literature and the control group, there was no increase in our double-J catheter location rate after endovisional technique $(\mathrm{p}=0.591)$.

We preferred general anesthesia in all our patients in order to provide better patient relaxation and to prevent variable breathing movements. Unwanted preoperative complications such as ureter perforation $(0.6 \%)$, mucosal damage (2-20\%) and urine extravasation may happen in RIRS. Uretral narrowing may be observed in a $0.5 \%$ ratio preoperatively $(8,22,27,28)$.

Serious mucosal damage or ureter injury or bleeding affecting visual quality were not observed in any of the patients in which this technique was used. Postoperative urine extravasation and ureteral narrowing was never detected.

In this study it was also observed that ureteral edema and mucosal damage was less frequent and that bladder neck and urethral injuries, edema and urethral mucosal damage were less frequent in patients whose sheaths were placed with this technique.

Major complications were not observed in both groups according to the modified Clavien system. Minor complication rate was $26.3 \%$ in the endovision group according to the modified Clavien system and $40.9 \%$ in the control group ( $\mathrm{p}=0.032)$.

The results of our study suggests that "Endovisional technique" for placement of ureter access sheath in RIRS safe, shortens operation and fluoroscopy duration and decreases major ureteral injuries. Studies of larger series should be carried out to support our findings.

\section{ConcLusion}

"Endovisional technique" is considered to be an appropriate and useful technique in order to place the sheath safely in patients who has difficulty in ureteral access sheath placement and to decrease the duration of operation and fluoroscopy.

\section{References}

1. Huffman JL, Bagley DH, Lyon ES. Extending cystoscopic techniques into the ureter and renal pelvis. Experience with ureteroscopy and pyeloscopy. JAMA. 1983; 250:2002-5.

2. Turk C, Knoll T, Petrik A, et al. European Association of Urology. Guidelines on Urolithiasis. 2012; 1-102.

3. Papatsoris A, Sarica K. Flexible ureterorenoscopic management of upper tract pathologies. Urol Res. 2012; 40:639-646.

4. Stern JM, Yiee J, Park S. Safety and efficacy of ureteral access sheaths. J Endourol. 2007; 21:119-23.

5. Auge BK, Pietrow PK, Lallas CD, et al. Ureteral access sheath provides protection against elevated renal pressures during routine flexible ureteroscopic stone manipulation. J Endourol. 2004; 18:33-6.

6. L'Esperance JO, Ekeruo WO, Scales CD Jr, et al. Effect of ureteral access sheath on stone- free rates in patients undergoing ureteroscopic management of renal calculi. Urol. 2005; 66:252-5.

7. Kourambas J, Byrne RR, Preminger GM. Does a ureteral access sheath facilitate ureteroscopy? J Urol. 2001; 165:789-93.

8. Traxer O, Thomas A. Prospective evaluation and classification of ureteral wall injuries resulting from insertion of a ureteral access sheath during retrograde intrarenal surgery. J Urol. 2013; 189:580-4.

9. Pietrow PK, Auge BK, Delvechio FC, et al. Techniques to maximize flexible ureteroscope longevity. Urol. 2002; 60:784-8.

10. Takayasu H, Aso Y. Recent development for pyeloureteroscopy: guide tube method for its insertion into the ureter. J Urol. 1974; 112:176-8.

11. Newman RC, Hunter PT, Hawkins IF, Finlayson B. The ureteral access system: a rewiev of the immediate results in 43 cases. $J$ Urol. 1987; 137:380-3.

12. Newman RC, Hunter PT, Hawkins IF, Finlayson B. A general ureteral dilator- sheathing system. Urol. 1985; 25:287-8.

13. Mona M, Dretler SP, Landman J, et al. Maximizing ureteroscope deflection. "play it straight" Urology. 2002; 60:902-5.

14. Vanlangendonck R, Landman J. Ureteral access strategies: proaccess sheath. Urol Clin North Am. 2004; 31:71-81.

15. Abrahams HM, Stoller ML. The argument against the routine use of ureteral access sheaths. Urol Clin North Am. 2004; 31:83-7.

16. Lallas CD, Auge BK, Raj GV, et al. Laser Doppler flowmetric determination of ureteral blood flow after ureteral access sheath placement. J Endourol. 2002; 16:583-90

17. Monga M, Bhayani S, Landman J, et al. Ureteral access for upper urinary tract disease: the access sheath. J Endourol. 2001; 15:831-4.

18. Ozyuvali E, Resorlu B, Oguz U, et al. Is routine ureteral stenting really necessary after retrograde intrarenal surgery? Arch Ital Urol Androl. 2015: 31;87:72-5.

19. Hatipoglu NK, Bodakci MN, Penbegul N, et al. Our experiences on retrograde intrarenal surgery. Dicle Med J. 2014; 41:95-98.

20. Breda A, Ogunyemi O, Leppert JT, Schulam PG. Flexible ureteroscopy and laser lithotripsy for multiple unilateral intrarenal stones. Eur Urol. 2009; 55:1190-6.

21. Sofer M, Watterson JD, Wollin TA, et al. Holmium:YAG laser 
lithotripsy for upper urinary tract calculi in 598 patients. J Urol. 2002; 167:31-34.

22. Bozkurt IH, Yonguç T, Yartmoglu S. Retrograde intrarenal surgery outcomes without using an access sheat. Med J of Izmir Hosp. 2015; 19:15-20.

23. Wu NZ, Auge BK, Preminger GM. Simplified ureteral stent placement with the assistance of a ureteral access sheath. J Urol. 2001; 166:206-8.

24. Hollenbeck BK, Schuster TG, Faerber GJ, Wolf JS. Routine placement of ureteral stents is unnecessary after ureteroscopy for urinary calculi. Urol. 2001; 57:639-43.
25. Chen YT, Chen J, Wong WY, et al. Is ureteral stenting necessary after uncomplicated ureteroscopic lithotripsy? A prospective, randomized controlled trial. J Urol. 2002; 167:1977-80.

26. Rapoport D, Perks AE, Teichman JM. Ureteral Access sheath use and stenting in ureteroscopy: effect on unplanned emergency room visits and cost. J Endourol. 2007; 21:993-7.

27. Watterson JD, Girvan AR, Cook AJ, et al. Safety and efficacy of holmium: YAG laser lithotripsy in patients with bleeding diatheses. J Urol. 2002; 168:442-445.

28. Harmon WJ, Sershon PD, Blute ML, et al. Ureteroscopy: current practice and long-term complications. J Urol. 1997; 157:28-32.

\section{Correspondence}

Mehmet Giray Sönmez, MD (Corresponding Author)

drgiraysonmez@gmail.com

Medical Park Ankara Hospital, Department of Urology

Kent Koop quarter 1868. street Batıkent

Ankara, Turkey

Cengiz Kara, MD, Associate Professor

Medical Park Ankara Hospital, Department of Urology

Ankara, Turkey 